\title{
Examining the impact of the built environment on flood losses in Texas
}

\author{
S. D. Brody ${ }^{1} \&$ S. Zahran ${ }^{2}$ \\ ${ }^{1}$ Environmental Planning \& Sustainability Research Unit, \\ Department of Landscape Architecture and Urban Planning, \\ Texas A\&M University, USA \\ ${ }^{2}$ Department of Sociology, Colorado State University, USA
}

\begin{abstract}
Floods continue to pose the greatest threat to the property and safety of human communities among all natural hazards in the United States. While the link between urbanization and flooding is established, the degree to which specific characteristics of the built environment affect the level of damage sustained by a community has never been thoroughly investigated at the regional scale. Our study addresses this lack of research by examining the relationship between the built environment and flood impacts in Texas, which consistently sustains the most damage from flooding of any other state in the country. Specifically, we calculate property damage resulting from 423 flood events over a five year period from 1997 and 2001 at the county level. We identify the impact of several built environment measures, including wetland alteration, impervious surface, and dams on reported property damage while controlling for biophysical and socioeconomic characteristics. Statistical results suggest that naturally occurring wetlands play a particularly important role in mitigating flood damage. These findings provide guidance to planners and flood managers on how to most effectively mitigate the costly impacts of floods at the community level.

Keywords: wetland alteration, flooding, Texas, Florida, wetlands, sprawl.
\end{abstract}

\section{Introduction}

Floods continue to pose the greatest threat among all natural hazards to the property, safety, and economic well-being of human communities in the United 
States (U.S.). According to the ASFPM [1], the economic impact from floods is estimated in the billions of dollars annually and the rate of damage has been steadily increasing. For example, Kunreuther and Roth [2] estimate \$22 billion in flood losses from 1949-1988 in the U.S. compared to $\$ 80$ billion from 19891997. This evident spike in flood-related property damage cannot be explained away by inflation in monetary systems or straight population growth. The rise cost of floods is, instead, driven by the manner in which humans plan for and subsequently develop their communities. Individual and community-based decisions pertaining to where buildings and impervious surfaces are concentrated, and the degree to which the overall hydrological system is altered, are exacerbating the losses resulting from repetitive floods. Increasing development associated with residential, commercial, and tourism activities, particularly in coastal and low-lying areas, has diminished the capacity of hydrological systems (e.g. watersheds) to naturally hold and store surface water run-off. As a result, private property, households, and the economic well-being of coastal communities are increasingly vulnerable to the risks of repetitive flooding events.

While the importance of maintaining the integrity of hydrological systems is well understood, the degree to which the built environment affects the level of damage sustained by a community has never been thoroughly investigated at the regional scale [3]. Aside from small-scale case studies conducted within a single watershed or jurisdiction, no study to date has thoroughly tested the impact of the human built environment based on multiple flood events over time, at large spatial scales, and controlling for multiple biophysical and socioeconomic characteristics.

Our study addresses this lack of research by examining the relationship between the built environment and flood impacts in the eastern portion of Texas. Texas is an ideal study area since it consistently has the most deaths and damages from flooding of any state. Of the 42 flood events listed as causing more than a billion dollars in damage between 1980 and 1998, four were in Texas [4]. According to Federal Emergency Management Agency (FEMA) statistics on flood insurance payments from 1978 to 2001, Texas suffered \$2.25 billion dollars in property loss, more than California, New York and Florida combined.

First, we calculate property damage resulting from 423 flood events over a five year period from 1997 and 2001 at the county level. Second, using multiple regression analysis, we identify the impact of several built environment measures including wetland alteration, impervious surface, and dams on reported property damage while controlling for biophysical and socioeconomic characteristics. Results from our study provide important information to environmental planners and flood managers on how development and modifications of natural landscapes adversely impact flood outcomes. Such information is critical given the continued development of coastal areas and the increasing vulnerability of human populations to inland coastal flooding. Our findings may thus provide guidance on how to build more sustainable, resilient communities over the long term. 


\section{Adverse impacts of the built environment on flooding}

In the U.S., rapid growth and sprawling development patterns have contributed to a marked increase in urbanization and built-up land uses. A major component of urbanization and contributor to flood occurrence is the increase in impervious surfaces. The link between impervious surface coverage and floods has been established since the late 1960s [5]. As the area of impervious surface coverage increases, there is a corresponding decrease in infiltration and an increase in surface runoff [6]. According to Arnold and Gibbons [7], as the percent catchment (i.e. drainage basin) impervious surface cover increases to $10-20 \%$, runoff increases twofold.

The urban built environment has also been linked to increased peak discharges [8]. In this instance, the lag time (time difference between the center of precipitation volume to the center of runoff volume) is compressed, resulting in floods that peak more rapidly [9]. For example, Rose and Peters [10] report peak discharge increases of approximately $80 \%$ in urban catchments with $50 \%$ impervious area. Flood discharge in proportion to impervious surface cover were at least $250 \%$ higher in urban compared to forested catchments in Texas and New York after similar storms.

The relationship between urban development and flooding depends not only on the amount of impervious surface generated, but specifically where in the hydrological landscape that surface is located. When urbanization and associated impervious surface coincide with the alteration of naturally occurring wetlands, flooding can be further accentuated. This is because wetlands are believed to provide natural flood mitigation by maintaining a properly functioning water cycle [11]. Overall, research suggests that wetlands may reduce or slow downstream flooding. In a comprehensive literature review, Bullock and Acreman [12] found that for 23 of the 28 studies on wetlands and flooding, "floodplain wetlands reduce or delay floods" (p. 366).

Initial research on the role wetlands can play in reducing flooding examined the differences between drained and natural wetlands. These studies generally showed that undrained peat bogs reduce low-return period flood flow and reduce overall storm flows when compared to their drained counterparts. Research utilizing simulation models also suggests that wetlands play a flood-reducing role. Ogawa and Male [13] analyzed a simulation model to evaluate the protection of wetlands as a flood mitigation strategy. Based on four scenarios of downstream wetland encroachment ranging from $25-100 \%$ loss, the authors found that increased encroachment resulted in significant increases in peak flow. Research based on direct observation also supports the notion that naturally occurring wetlands can help reduce flood intensity. For example, based on an experiment that involved constructing wetlands along the Des Plaines River in Illinois, it was found that a marsh of only 5.7 acres could retain the natural runoff of a 410-acre watershed. 


\section{Research methods}

\subsection{Sample selection}

As mentioned above, we selected for analysis 423 damaging flood events across a 37 county study area in eastern Texas between 1997 and 2001. This area is ideal for examining the impact of the built environment on inland flooding (excluding tidal or surge-based flooding) for the following reasons: 1) Texas suffers significantly more property damage from floods than any other state in the country; 2) these floods tend to be spatially repetitive over time; 3 ) eastern Texas has been experiencing large increases in impervious surfaces and alteration of wetlands associated with rapid coastal development; and 4) these development patterns vary spatially across counties.

\subsection{Concept measurement}

The dependent variable, flood property damage, was measured as the total dollar loss (in CPI adjusted 1997 US\$) from a flood event. This variable was logtransformed to approximate a Gaussian distribution. Data on flood property damage are collected from the SHELDUS database at the Hazard Research Lab at University of South Carolina, Columbia.

To properly estimate the effect of built environment on flood related property damage, one must control for storm intensity and flood duration. In our model, we measured four biophysical predictors of flood damage: precipitation (day of the flood event), precipitation (day before the flood event), flood duration, and floodplain overlap. Precipitation (day of the flood event) and precipitation (day before the flood event) are measured as the average surface precipitation (in hundredths of an inch) recorded by county weather stations. We measured Flood duration as a dichotomous variable. A flood event was assigned a score of 1 if it lasted more the one day, and a score of 0 if it lasted 1 full day or less. Floodplain overlap was calculated as the percentage of a county's area within a FEMA defined 100-year floodplain (delineated areas that have a one percent chance of flooding in any one year) using Geographic Information Systems analytical techniques.

We measured and analyzed three built environment variables shown to affect the degree of community-wide flood damage. We calculated impervious surface as the percentage of land covered by impervious surfaces (i.e. pavement, buildings, etc.) in a county area. Impervious surface was developed using GeoCover satellite imagery during 1990 and 2000 from NASA Stennis Space Center. Wetland alteration was measured as the cumulative total of spatiallydefined wetland permits the day of a flood event. Wetland permits, required under Section 404 of the Clean Water Act, enable an applicant to alter a naturally occurring wetland for a construction project and were obtained from the U.S. Army Corp of Engineers (USACE) District Office in Galveston, Texas. Of the 10,921 permit records received from the USACE, 7,957 had sufficient 
information to be located geographically. Finally, the number of dams in a county area was tabulated to estimate the extent to which water embankments function to reduce flood property damage. Locations of dams were obtained from the U.S. Army Corps of Engineers and summed by each county unit.

We measure two socioeconomic predictors of flood property damage. FEMA rating scores are based on the FEMA Community Rating System (CRS). The CRS promotes mitigation of flood damage through insurance premium discounts. Credit points are assigned for 18 measures organized into four broad categories of flood management: public information, mapping and regulation, flood damage reduction, and flood preparedness. Discounts range from 5 to 45 percent applied to all written policies in a community. Median household income was measured as the sum of money income received in calendar year 1999 by all household members 15 years old and over. We included household income in the statistical model to control for the degree of wealth and by proxy the value of structures in each county.

\section{Results}

From 1997 to 2001, 423 flood events caused over \$320 million in reported property damage among Texas coastal counties. The average amount of damage per flood during this time period was $\$ 423,765.90$. Over the five-year study period, Guadalupe County incurred the most damage in the sample with approximately $\$ 89$ million over 20 flood events. Neighbouring Gonzales County experienced a similar degree of flood damage (almost \$89 million) over 23 events. In contrast, Hidalgo County reported the lowest amount of damage, $\$ 2,000$ for one only event (see Figure 1).

Multivariate regression analyses with standardized coefficients indicate which factors most influence the degree of flood damage in eastern Texas (Table 1). We added the following three suites of variables sequentially to the model to test their effects both individually and as a group: biophysical, built, and socioeconomic environments. Biophysical variables as a whole explain the most variance on the dependent variable (over 29\%). Adjusting for precipitation the day of the flood event, rainfall amount the day before the actual flood event is the strongest predictor of damage, followed by the duration of a flood (where $\mathrm{p}<0.05$ ). Precipitation the day of the flood event and the percentage of a county within the 100-year floodplain are, by comparison, weaker yet still statistically significant predictors of flood damage (where $\mathrm{p}<0.1$ ).

Of the built environment variables examined, wetland alteration is the strongest partial correlate of flood property damage $(\beta=0.1161)$. Increasing amounts of impervious surfaces within each county also contributes to marked increases in flood damage (where $\mathrm{p}<0.1$ ). The presence of dams as flood control devices appears to reduce the amount of damage $(\mathrm{p}<0.1)$ almost to the same degree to which damage is exacerbated by wetland alteration $(\beta=-0.1061)$. In effect, what is gained by dams in the mitigation of flood outcomes is statistically offset by development activities in wetlands. 


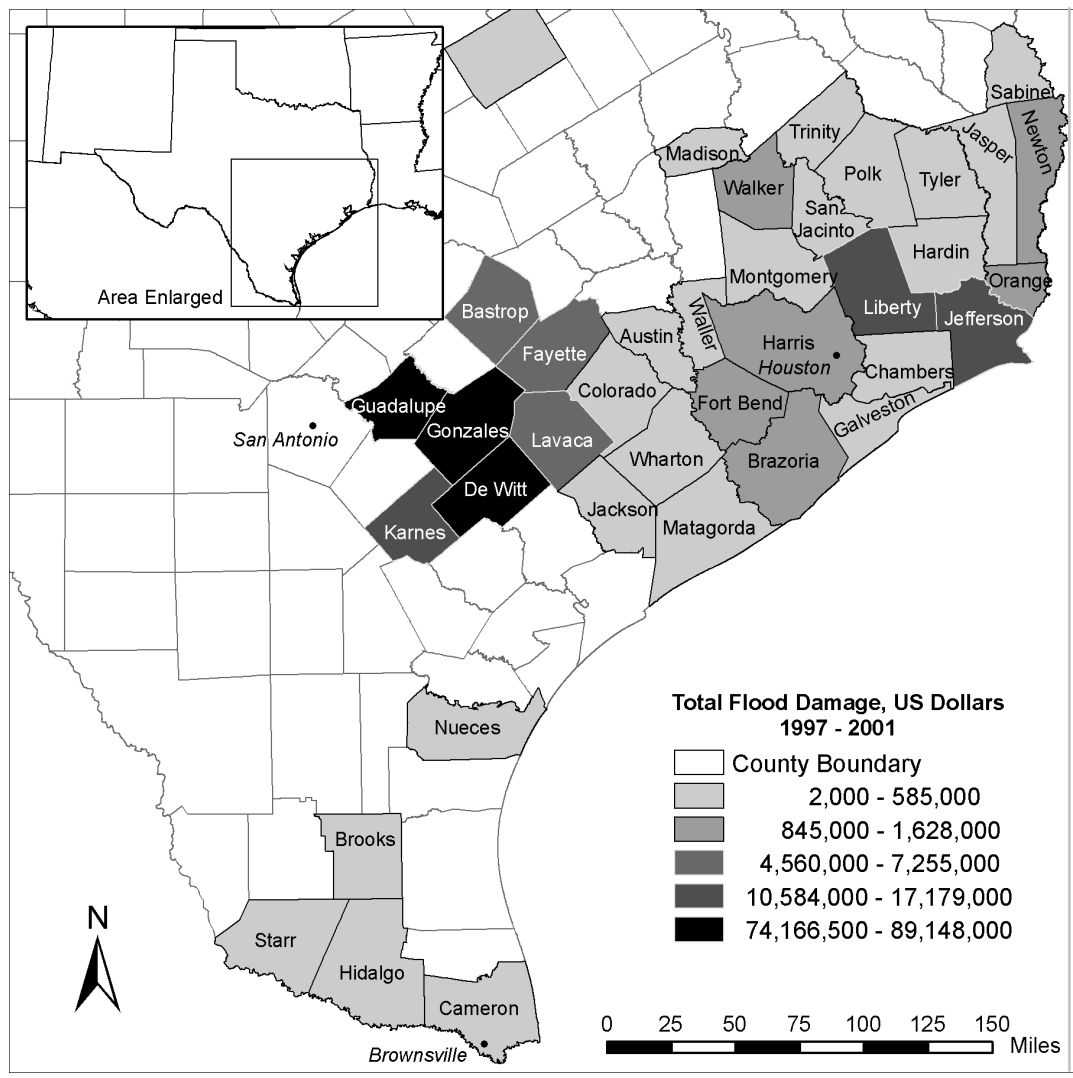

Figure 1: $\quad$ Cumulative flood damage from 1997 to 2001.

In the fully-specified model containing socioeconomic variables, approximately $32 \%$ of variation in flood related property damage is explained. Counties with higher FEMA CRS scores and corresponding reductions in insurance premiums experience lower amounts of flood damage at the 0.1 level of significance. The effect size of FEMA rating $(\beta=-0.1073)$, summarizing the flood mitigation efforts undertaken by a locality, rivals the effect size of precipitation the day of a flood event $(\beta=-0.1504)$. Increasing amounts of precipitation the day before the actual flood event remains the strongest predictor among biophysical variables examined. Wetland alteration continues to have the largest effect on the dependent variable among built environment variables $(\beta=$ 0.1581). The predictive power of the number of dams within a county, representing structural solutions to flood mitigation, decreases $(\beta=-0.0944$, $\mathrm{p}<0.1$ ) with the addition of socioeconomic controls. 
Table 1: $\quad$ Regression models predicting property damage.

\begin{tabular}{|c|c|c|c|c|c|c|}
\hline & B & Beta & $\mathbf{B}$ & Beta & $\mathbf{B}$ & Beta \\
\hline \multicolumn{7}{|c|}{ Natural Environment Variables } \\
\hline $\begin{array}{l}\text { Precipitation (day of } \\
\text { event) }\end{array}$ & $\begin{array}{l}0.051 \dagger \\
(0.027)\end{array}$ & 0.163 & $\begin{array}{l}0.046 \dagger \\
(0.028)\end{array}$ & 0.147 & $\begin{array}{l}0.047 \dagger \\
(0.027)\end{array}$ & 0.150 \\
\hline $\begin{array}{l}\text { Precipitation (day } \\
\text { before event) }\end{array}$ & $\begin{array}{l}0.125^{* *} \\
(0.033)\end{array}$ & 0.308 & $\begin{array}{c}0.133 * * \\
(0.034)\end{array}$ & 0.327 & $\begin{array}{c}0.132 * * \\
(0.033)\end{array}$ & 0.323 \\
\hline Floodplain area & $\begin{array}{l}0.451 \dagger \\
(0.256)\end{array}$ & 0.066 & $\begin{array}{c}0.217 \\
(0.262)\end{array}$ & 0.032 & $\begin{array}{c}0.174 \\
(0.281)\end{array}$ & 0.025 \\
\hline Duration of flood & $\begin{array}{c}0.423 * * \\
(0.131)\end{array}$ & 0.197 & $\begin{array}{l}0.439 * * \\
(0.132)\end{array}$ & 0.200 & $\begin{array}{c}0.429 * * \\
(0.131)\end{array}$ & 0.200 \\
\hline \multicolumn{7}{|c|}{ Built Environment Variables } \\
\hline Impervious surface & & & $\begin{array}{l}0.010 \dagger \\
(0.005)\end{array}$ & 0.082 & $\begin{array}{l}0.008 \dagger \\
(0.005)\end{array}$ & 0.070 \\
\hline Wetland alteration & & & $\begin{array}{l}0.000 * * \\
(0.000)\end{array}$ & 0.116 & $\begin{array}{l}0.000 * * \\
(0.000)\end{array}$ & 0.158 \\
\hline Dams & & & $\begin{array}{l}-0.072^{*} \\
(0.040)\end{array}$ & -0.106 & $\begin{array}{l}-0.064 \dagger \\
(0.039)\end{array}$ & -0.094 \\
\hline \multicolumn{7}{|c|}{ Socioeconomic Variables } \\
\hline FEMA rating & & & & & $\begin{array}{l}-0.018 \dagger \\
(0.010)\end{array}$ & -0.107 \\
\hline $\begin{array}{l}\text { Median household } \\
\text { income }\end{array}$ & & & & & $\begin{array}{c}6.3 \mathrm{e}-06 \\
(5.1 \mathrm{e}- \\
06)\end{array}$ & 0.060 \\
\hline Constant & $\begin{array}{l}3.842 * * \\
(0.076)\end{array}$ & & $\begin{array}{c}3.750 * * \\
(0.085)\end{array}$ & & $\begin{array}{c}3.586^{* *} \\
(0.167)\end{array}$ & \\
\hline $\mathrm{N}$ & 423 & & 423 & & 423 & \\
\hline $\mathrm{F}$ & 20.80 & & 15.96 & & 12.88 & \\
\hline Probability $>$ F & 0.000 & & 0.000 & & 0.000 & \\
\hline R-squared & 0.298 & & 0.313 & & 0.318 & \\
\hline Root MSE & 0.713 & & 0.708 & & 0.707 & \\
\hline
\end{tabular}

\section{Discussion}

Analysis of the data indicates that specific characteristics of the human built environment in eastern Texas have an important influence on property damage resulting from floods, even when controlling for biophysical and socioeconomic factors. These findings provide guidance to planners and flood managers on how to most effectively mitigate the costly impacts of floods at the community level. First, as expected, flood damage is largely governed by the amount and duration of precipitation associated with a given storm. Yet, our data show that the timing of precipitation is particularly important in terms of its effect on the amount of resulting property loss. Heavy precipitation the day before the actual flood event is by far the strongest predictor of total property damage. This result may be a function of the delay between initial rainfall and resulting rise in water levels causing damage. It is therefore important for decision makers and the public to understand that heavy precipitation followed by sunny skies can still result in significant flood damage. 
Second, our results show that the alteration of naturally occurring wetlands is the most important built environment indicator of flood damage. Altering or removing a wetland to construct parking lots, roads, rooftops, etc. effectively eliminates its ability to capture, hold, and store water runoff. The planning goal in this situation is to allow development to proceed without reducing the hydrological function and value of wetland systems. Achieving this goal will involve identifying the location of naturally occurring wetlands and then protecting these critical areas through local land use policies, such as zoning restrictions, land acquisition programs, clustered development, density bonuses, etc.

Third, structural solutions to flood mitigation significantly reduce flood damage as evidenced by the performance of our variable measuring the number of dams in each county. However, based on the standardized coefficients in our fully specified model, wetlands may be more effective than dams in mitigating property loss over time. Dams are also extremely costly mitigation alternatives, can exacerbate development in flood prone areas out of a false sense of security [14], and can present a hazard in themselves in the case of structural failure.

Fourth, our empirical results suggest that mitigation measures under FEMA's CRS program reduce property damage from floods. Communities that engage in mitigation activities related to public information, mapping and regulations, and flood damage reduction in exchange for reduced flood insurance premiums experience significantly lower amounts of flood related property damage. In fact, the effect of CRS participation appears to reduce community-wide flood damage more than dams, which are far more costly.

In addition to comparing the relative effects of predictor variables on flood damage, because our dependent variable is measured in dollar figures, we can address the question: what is the price of a wetland permit and what are the economic tradeoffs of various mitigation measures? Based on our fully specified model, a single wetland permit translates into an average of $\$ 211.88$ in additional property damage per flood. By comparison, the presence of a dam results in a $\$ 27,290$ dollar decrease in average property damage for each flood event in our sample. This means that, on average, only 129 wetland alteration permits offset the flood-reducing effects of dams. Given the expense of building dams, their negative environmental impacts, and the possibility of structural failure, protecting naturally occurring wetlands may be a more rational policy.

The economic gains obtained by non-structural mitigation measures are also evident for those counties participating in the FEMA CRS program. Based on our results, a unit increase in CRS equals approximately $\$ 7,797$ dollars less in property damage per flood. Because FEMA scores move in $5 \%$ increments, a real unit increase in FEMA rating corresponds to a $\$ 38,989$ reduction in average cost per flood. If all localities in our sample achieve the maximum premium discount of $45 \%$, the average damage of a flood is reduced to under $\$ 100,000$, roughly a quarter of the average flood in our study. Thus, mitigation is an essential component in any flood reduction program aimed at protecting the property and safety of communities. 


\section{Conclusion}

Our study provides evidence that flood damage is not solely a function of rainfall, but also driven by the scale and type of human development. Furthermore, property damage is influenced not so much by how much is built, but precisely where within an ecological system development unfolds. Locationbased development decisions thus become critical to mitigating property damage from floods in the future. As stated by a 1966 Federal Task Force, "floods are an act of God; flood damages result from the acts of [people]" (TFFFCP [15, p. 14]). Assuming that communities have a choice as to where and how they develop, decision makers are wise to build places to live, work, and recreate that simultaneously maintain the functionality of hydrological systems and the flood moderating features of naturally occurring wetlands.

\section{Acknowledgements}

This paper is based on research supported by the U.S. National Science Foundation Grant No. CMS- 0346673. The findings and opinions reported are those of the authors and are not necessarily endorsed by the funding organization.

\section{References}

[1] Association of State Floodplain Managers, National Flood Programs in Review - 2000, ASFM: Madison, Wisconsin, 2000.

[2] Kunreuther, H. J. \& Roth, R. J. Paying the Price: The Status and Role of Insurance Against Natural Disasters in the US, John Henry Press: Washington, D.C., 1998.

[3] Peilke, R. A., Flood Impacts on Society: Damaging floods as a framework for assessment, Floods, D.J. Parker (ed.) Routledge: New York and London, pp. 133-155, 2000.

[4] NCDC (National Climatic Data Centre), Billion Dollar U.S. Weather Disasters, http://www.ncdc.noaa.gov/ol/reports/billionz.html, 2000.

[5] Leopold, L. B., A View of the River, Harvard University Press: Cambridge, MA, 1994.

[6] Paul and Meyer, Streams in the Urban Landscape. Annual Review of Ecological Systems, 32, pp. 333-365, 2001.

[7] Arnold, L. A. \& Gibbons, C. J., Impervious Surface Coverage-the emergence of a key environmental indicator. Journal of the American Planning Association, 62, pp. 243-258, 1996.

[8] Brezonik, P. L. \& Stadelman, T. H., Analysis and Predictive Models of Stromwater Runoff Volumes, Loads and Pollutant Concentrations from Watersheds in the Twin Cities Metropolitan Area, Minnesota, USA. Water Resources, 36, pp. 1743-1757, 2002.

[9] Hirsch, R. M., Walker, J. F., Day, J. C. \& Kallio, R., The Influence of Main on Hydrological Systems. Surface Water Hydrology, vol. 0-1, ed. 
M.G. Wolman \& H.C. Riggs, Geological Society of America: Boulder, CO, pp. 329-359, 1990.

[10] Rose, S. \& Peters, N., Effects of Urbanization on Streamflow in the Atlanta Area (Georgia, USA): a comparative hydrological approach. Hydrological Proceedings, 14, pp. 1441-1457, 2001.

[11] Mitch, W. J. \& Gosselink, J. G., Wetlands, $3^{\text {rd }}$ ed., John Wiley \& Sons: New York, NY, 2000.

[12] Bullock, A. \& Acreman, M., The role of wetlands in the hydrological cycle. Hydrology and. Earth System Sciences, 7(3), pp. 358-389, 2003.

[13] Ogawa, H. \& Male, J. W., Simulating the Flood Mitigation Role of Wetlands. Journal of Water Resources Planning and Management, 112(1), pp. 114-128, 1986.

[14] Tobin, G. A., The Levee Love Affair: A Stormy Relationship. Water Resources Bulletin, 31, pp. 359-367, 1995.

[15] TFFFCP (Task Force on Federal Flood Control Policy), A Unified National Program for Managing Flood Losses, Report No. 67-663, U.S. GPO: Washington, D.C., 1966. 